\title{
PHENOLOGY OF MACROPHYTES OF SAGAR LAKE (M.P.)
}

\author{
Arti Gupta \\ Department of Botany \\ Dr. H.S. Gour Vishwavidyalaya \\ Sagar (M.P.) - 470002, India
}

\begin{abstract}
The paper deals with phenological data of ten macrophyte species growing in Sagar lake. Phenograms of Eichhornia crassipes, Hydrilla verticillata, Ipomoea aquatica, Jussiaea repens, Pistia stratiotes, Trapa bispinosa and Vallisneria spiralis have been presented.
\end{abstract}

Key words: Phenology, Sagar lake.

Phenology is an important natural phenomenon recurring periodically with respect to the change of season and physical environment.

Sagar is situated in north of the tropic of Cancer at $32^{\circ} 50^{\prime} \mathrm{N}$ and $78^{\circ} 45^{\prime} \mathrm{E}$. The average rainfall is about $1,237 \mathrm{~mm}$. Atmospheric temperature shows a seasonal variation with maximum $\left(44.4^{\circ} \mathrm{C}\right.$ and minimum $\left(8.3^{\circ} \mathrm{C}\right)$ in the months of May and January, respectively. Sagar lake is a shallow rain fed lake with 730 ha catchment area and is situated in the heart of city. As per old records the area of lake was 580 ha, but the present area of the lake is 81 ha only with mean depth of $3 \mathrm{~m}$. The maximum depth is $8 \mathrm{~m}$ with an average drawdown by $3 \mathrm{~m}$. The lake is mainly rained and receives runoff water from surrounding hills. The present lake is divided into two parts by a soft rock road, a main lake which occupies an area of 68 ha, and a small lake which is 13 ha. A minor organic pollution of the lake also occurs due to increasing intensities of outside factors like entry of sewage, hospital wastes, opening of drainage, bathing, washing wallowing of cattle.
There is not much published information on the aquatic and wetland vegetation of Madhya Pradesh. The present paper provides a phenological data of some aquatic plants of Sagar lake.

Phenological data were recorded in each month from January 2003 to December 2003 of Sagar lake. All six phenological events were noted. The phenogram and symbol legend used for different stages are shown in Fig. 1.

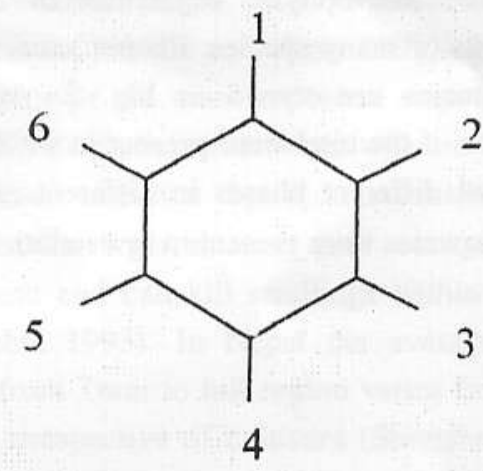

Fig. 1. Phenogram showing different phenophases (1-6). 1- Germination, 2Vegetative growth, 3- Flowering, 4Fruit formation, 5- Seed maturation, and 6- Death. 


\begin{tabular}{|c|c|c|c|c|c|c|c|c|c|c|c|c|}
\hline Name of Plants & & & & & & & & & & & & \\
\hline Eichhort & Q & 0 & & $\alpha$ & Q & 0 & 0 & C) & Q & R & & \\
\hline 2. Hydrilla verticillata & 0 & Q & D & 0 & V & $\gamma$ & $\gamma$ & 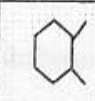 & a & Q & & \\
\hline 3. Iromooa aquatica & 소 & A & 소 & M & 0 & 0 & 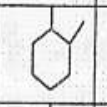 & $\gamma$ & a & a & & \\
\hline 4. Jussiazar & $\widehat{\Omega}$ & A & A & $\widehat{R}$ & م & $P$ & 0 & 0 & $\sigma$ & $Q$ & 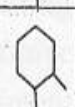 & \\
\hline & . & 0 & $\sigma$ & $\widetilde{\alpha}$ & A & ما & 全 & X & Q & P & & \\
\hline & al & $Q$ & Q & - & .. & -. & - & $\gamma$ & $\gamma$ & $\sigma$ & & \\
\hline 7. Nymphoides indicum & $Q$ & $Q$ & 0 & .. & -. & .- & - & $\sigma$ & $\sigma$ & Q & Y & \\
\hline 8. Pristia strat & $Y$ & Y & $a$ & a & $a$ & $a$ & al & a & Q & Q & Y & \\
\hline 9. Trapab bispinsosa & $D$ & 0 & $\gamma$ & O & $\sigma$ & $\checkmark$ & $\alpha$ & $Q$ & Q & Q & & \\
\hline Vallisneria spiralis & Q & Q & 1 & 0 & $\mathrm{D}$ & $\mathcal{Y}$ & $\gamma$ & $\checkmark$ & 0 & $\widetilde{Q}$ & $a$ & \\
\hline
\end{tabular}

Fig. 2. Phenograms of macrophytes showing phenophases.

The macrophytic vegetation of Sagar lake consists of many species. Phenophases of selected 10 species are shown in Fig. 2. About seven species of the total were present in whole year and showed different phases in different months. But three species were present in few months.
It has been clearly observed that the flowering period of four species are winter to spring seasons, three species flower in rainy season, one species in summer and two species in mostly whole year. 